\title{
RETRACTED ARTICLE: The effects of each beta-glucosidase gene deletion on cellulase gene regulation in Neurospora crassa (online publication: DOI 10.1007/s10482-013-9972-7)
}

\author{
Weihua Wu • Takao Kasuga • Lynn Nguyen • \\ Zhiliang Fan
}

Received: 24 April 2013/Accepted: 9 July 2013/Published online: 3 September 2013

(C) Springer Science+Business Media Dordrecht 2013

Takao Kasuga and Zhiliang Fan were listed as coauthors without their acknowledgement and would like to be removed from the author's list.

This article is retracted on request of Weihua $\mathrm{Wu}$ due to inconsistent errors of intracellular and total beta-glucosidase activities assay and the mycelia weight measurement in this paper. These errors lead to inaccurate results of total and intracellular betaglucosidase activities, and the normalized endoglucanases and exoglucanases activities and therefore compromise the partial conclusions of this publication.

W. Wu $(\bowtie) \cdot$ L. Nguyen · Z. Fan

Biological and Agricultural Engineering Department, University of California, One Shields Avenue, Davis, CA 95616, USA

e-mail:whwu@ucdavis.edu

\section{T. Kasuga}

Department of Plant Pathology, University of California,

One Shields Avenue, Davis, CA 95616, USA

T. Kasuga

United States Department of Agriculture, Agricultural

Research Service, Washington, DC, USA 